\title{
The Profile of the Fanatical Terrorist
}

\author{
Gavril Cornutiu \\ Clinic of Psychiatry, Faculty of Medicine and Pharmacy, University of Oradea, Oradea, Romania \\ Email: g_cornutiu@yahoo.com
}

Received 20 February 2016; accepted 18 April 2016; published 21 April 2016

Copyright (C) 2016 by author and Scientific Research Publishing Inc.

This work is licensed under the Creative Commons Attribution International License (CC BY).

http://creativecommons.org/licenses/by/4.0/

c) (i) Open Access

\section{Abstract \\ The text is a partial synthesis of essential knowledge to date, with the author's own conceptual development, regarding fanaticism, population groups at risk and personality profile of the fanatical terrorist, from a cultural point of view.}

\section{Keywords}

\section{Fanatical Terrorist, Fanatical, Population Groups at Risk, Culture and Fanaticism}

The tectonic plates of human geology are shaken once again. The current turmoil of the depths of humanity is just as dramatic as those at the end of the age of antiquity. If then, humanity was punished with barbarian raids; today, "God's whip” is terrorism. This issue needs to be approached from all perspectives for a better understanding of this kind of behaviour. There are two prerequisites to this idea.

- One must not confuse psychological and psychiatric diagnose.

- One must not confuse pathology of the individual with cultural pathology. It must be asserted that a universe does not consist of a point of view and an explanatory model only. One must also point out that the more sensitive a theme is, the more impetuous a clear definition of notions is.

\section{Introduction}

The fanatic is defined as the person who, while adhering rigidly and exclusively to an idea or belief, puts himself unconditionally in the real or imaginary service of defending or promoting it, regardless of risk, be it even a vital one. The fanatic actively refuses any other option.

Violence is considered to be a brutal behaviour of the verbal or physical type, that a person uses, both as their nature, or reactively, by which a person irritates or hurts the people around. Violence is a way of relating and has no clear reference. Aggression has a purpose and a reference in the situation in which a person attacks other people and causes, or risks causing mental or physical trauma. It can be reactive-emotionally charged, or programmed, calculated and disregarding consequences. 
The terrorist is the person who promotes their interests by means which provoke fear and terror and who, in the name of his ideas or interests, can kill a person or a group of people. Terror is always calculated and disregards consequences. By combining the notions of fanatic and terrorist one arrives at the definition of the fanatical terrorist. Relationally, the two notions could form groups of features, targeting the relationship of the person with themselves, with their real or imagined surroundings and with other people. In this case, the last group of features is of interest. Therefore, the fanatic serves an idea. He has a messianic role through ideas usually encompassing the general well-being of humankind or some parts of it. The messianic fanaticism appeared in history with monotheistic religions. The first Christians died for their belief. The Crusaders followed. There are still fundamentalist cults today, as well. But the fundamentalist Christian fanaticism did not only generate messianically argued sacrifices but also murders, backed by the same messianic reasoning. Let us only remember the Inquisition.

The same thing can be asserted about other monotheistic religions. The sacrificial or criminal fanaticism did not only come in religious forms. Other messianic ideas such as Nazism or Communism generated sacrifice-type behaviour, including life sacrifice, and criminal behaviour in order to protect a messianic idea. When any given idea outside the personal interest becomes rigid, intolerant and exclusive and generates a pseudo-religious conviction, it becomes messianic and recruits its “fighters” among predisposed personalities. In "sub-clinical doses" one can regard fanatics as rigid and intolerant of bureaucracy. In order to give a typical example of terrorism it is enough to mention the current Islamic terrorism. One thing to notice is the fact that Christianity was initially exclusive and intolerant, while today it has become so tolerant that it risks its own suffocation. The Islam was initially tolerant (Mohammed's physician was a Christian), yet today it exercises absolute intolerance. One can notice the swing from an extreme to the other, from sacrificial messianic fanaticism to criminal messianic fanaticism and the other way around. In this regard, a great truth spoken by Noica (2009), is overlooked "truth can only be accurate, but accuracy can be without truth”.

At this historical moment when digitalization of human thinking has become an emphatic trend under the pressure of technology, this philosophical note is extremely important. This means that mathematical truth is not higher than poetic truth. The two combined reveal the human truth. Within the frame of the Romanian battle against corruption, a public servant at the National Financial Agency, highly committed to becoming a crusader in this battle, descends at the local food market where he comes across an old lady selling nettle at the entrance, as she was unable to pay rent for a regular table among other sellers/producers. The price the old lady was charging was 5 Romanian lei (the equivalent of about 1 Euro) for a bundle. The committed crusader requested her license to produce the goods she was selling, but nobody produces nettle. It only grows in the wild. The clerk proceeds to confiscating her merchandise and accuses her of breaking the law. What is to be seen here, beyond the absurdity of the clerk, is how easily one can become intolerant in the name of any given generous idea and how wide the gate of intolerance and opportunism is. Fanaticism is a conviction of intensity and rigidity bordering the limits of normality, leading to a one-way directed attitude, to messianic and intolerant ideas, which, in a given context, can develop into behaviour.

Therefore, the fanatical terrorist is a person who has reached (or has been brought to) an exclusive adherence to a belief, who has an extreme rigidity, refusing any other version of the discussed idea's reality, capable of murder and sacrifice by any means in order to impose the idea they adhere to, primarily through crime and terror.

\section{The Nature of the Fanatic}

The fanatic is a type of personality amongst a limited number of possible types. Even if in appearance, personality traits seem to be a descriptive jungle "the truth is that the traits which determine human nature are numerous but not infinite” (Leonhard, 1979). Allport lists 17,000 descriptive adjectives in the English language. They are grouped in antonyms such as good/bad, hardworking/lazy etc. Antonyms can be grouped according to their relational valences to describe the relationship of the person with themselves, with the general accepted values, with the surrounding reality and with peers. Of main interest are the last two groups mentioned above, as well as the relation with accepted values of the community of origin. From the point of view of peer relations "some aspirations are egoistic, other are altruistic” (Leonhard, 1979). The imbalance between intensity and dominance leads to emphasis on one trait over another, or, what Leonhard calls accentuated personality traits. The ratio between 
these traits is much more complex as it is dependent on the ratio of all traits, added to the internal neuropsychological and peristatic factors, the final result of this unbalance determining the behaviour of an individual.

The imbalance may be possible one way or another. Total abandonment of selfish aspirations and their replacement with altruistic aspirations, in which case the personality becomes devoted to an altruistic cause is possible. There are famous examples to be cited here, such as Mother Theresa's devotion to Christian principles through the power of faith. The sense of duty, as deriving from a general cause, generated the kamikaze behaviour in the Japanese, the sacrificial behaviour of young Nazi and robotic criminal behaviour in other Nazi. In communism, Che Guevara could be mentioned. As one could notice, the final expression of personality imbalance of the fanatical messianic type can be socially diverse, depending on the cultural background, all following the same path to development. According to Kant (1994), reason is "the faculty by which one derives the particular from the general”, i.e. proceeding deductively. The fanatic derives the general from the particular, thus proceeding inductively. By rooting in affections, logical mechanisms are reversed. Thus, the fanatic is the opposite of normality. On the other hand, knowledge is organised and systemised "by virtue of a principle" (Kant, 1994), so it is paradigmatically organised around an idea which is at the base of the paradigm and from which one cannot escape unless by acknowledging it. But the emotional implosion in religious beliefs makes awareness unlikely and difficult. A Christian who has reached a certain degree of intensity in his belief will stay captive in the Christian paradigm. The same principle applies to the Islamist, Buddhist, Mosaic or Hindu. Reason uses intelligence "in accordance to a purpose" (Kant, 1994), meaning that it always serves a purpose, which is the aim of the founding principle of the paradigm. In messianic ideas, there are no people, as people are flawed, subjected to criticism and can be separated. The fanatic has a cause derived from the messianic idea, not a human regiment, which may exist in any case and which becomes just an organisation frame, not a mobilizing spring. Particularly, once the emotionally grounded idea becomes messianic, it excludes any other emotional, empathetic or moral content deriving from empathy. Any type of messianic idea is possible. De Unamuno (1982) says that any idea is of use for the fanatic, and he fights, or commits crimes in the name of all his ideas. Note that these fanatics, these unstable people, these bonsai do not exist in nature. They must be made in order for someone to use them. They are the most efficient tools possible. The immediate conclusion is that it is not enough to sweep the water out of a flooded house if one does not close the tap, represented in this situation by the schools producing fanatics. The intensity and exclusiveness of adherence to the messianic idea grows progressively through paranoid mechanisms which transform any evidence into an argument to justify itself. The paranoid mental mechanisms do not mean paranoia or a paranoid personality type, but are also present in normal situations. Jealous ideas are experienced by most people but in normal situations they are immediately corrected. The difference is given not by species but by intensity, and "the best predictor for violence is previous violence in the established structure". Since the messianic idea is an endless and unattainable cause, the fanatic's final stage is-in his fight for a cause-always violent aggression.

\section{Predisposed Individuals}

One must avoid the confusion between accentuated personality types and personality disorders, the latter being pathological entities. Leonhard (1979), the father of this notion, asserts that "accentuated traits are less numerous than what is presented as variations" in actual normality but they have "the tendency to slide into abnormality”. For him, (Leonhard, 1979) "accentuated personalities manifest vocation for something out of the ordinary", both positive and negative. When "finding ourselves in the presence of a negative image we are inclined to assume a personality disorder exists" (Leonhard, 1979) and "in the case of a positive image we assume the existence of an accentuated personality". What the accentuated personality and paranoid personality disorder have in common is the trait called "the hyper-perseverance of emotion" (Leonhard, 1979), an affective disorder. What can be inferred so far from what has been presented is that the personological vulnerability of such individuals is emotional weakness in addition with insecurity, later hyper-compensated by defense mechanisms-in the Adlerian sense-focusing on a fixed, "saving" idea with rigid blockage of affect around it. The result is that the range of people who can be completely fanaticised are either still immature or adults with emotional instability, insecurity and chronical frustrations, who do not have any other chance of compensation. Still, these personality types are not sufficient. The culture offering the founding messianic idea promoted by propaganda and training schools is needed. The schools may be groups in which a We-ity takes the role of leader and teacher. 


\section{The Mechanism of Forging a Fanatical Bonsai}

The fanatic utopia occurs as a phantom (illusion) and then it embodies in the "conviction reality” (De Unamuno, 1982) on a vacant space or where other donating principles have been compromised. Eventually, utopia replaces reality. The fanatic does not dwell in reality-he disregards it. Therefore the fanatisation's first step is demolition and compromising any ordering principle (of empirical reality in the first place) so that to later plant the idea with super-individual potential (Christianity, Islamism, Mosaic, Communism, Nazism etc.). What happens next is an absolutisation of the fanatic conviction in relation to the relativisation of reality. The replacement of reality sense with the fanatic utopia leads to loss of inner freedom. The individual becomes addicted to the command of utopia as a biological automatism. Hence the calm is an indifference in action. Culturally, there are two measurement units of homicide in all cultures. The first is the one of low goals and corresponds to moral and terrestrial justice. The second one is the one of high goals and corresponds to "celestial justice”. Therefore, killing somebody for a low, earthly, egoistic goal is a crime. Alternatively, killing somebody for a high, super-individual goal is an act of courage, heroism and selflessness to attain the higher goal. It is a cultural defect. But do we have better measuring units today? Better in what sense? Is it preferable to abolish notions such as patriotism, mankind welfare or salvation of the masses? The problem is highly difficult, insolvable even! Let us remember some of our European absurd attempts. In the 17th century, Le Marquise de Sade (Carter, 1987) believed that the "hymen vow" must be eliminated for social reasons and that children should be denied the knowledge of their father, as they are "the children of the motherland". We should bear in mind that, in his day, Sade was deemed either guilty or a psychic case (he spent 32 years in prisons and lunatic asylums). For Christian fanatics, the children are the children of God and for Islamics they are the children of Allah. One of the first behavioural (and fundamental) experiences is of interpersonal relational origin (Oldham, Skodol, \& Bender, 2005). The fanatic has his first experiences annihilated unless they are firm and stable. They are replaced with "fresh new” ones. All ambitious individuals, discontented with the low level of their human validation, with their importance, will rush to accept new and promising ways of validation. So, the starting point is an emotionally unstable, insecure and chronically frustrated person who exhibits a minimal paranoiac structure (which is basically present in the structure of all normal individuals), in the presence of the dissatisfaction with the daily dullness and, culturally and in the presence of unstable value criteria. This type of people needs peer validation (Cornuțiu, 2004). The group pressure is directly inter-personal also by means of Newness-which bears social cultural values. Any person belongs to a number of groups which bring newness. The most important groups are the primary ones (family, relatives, friends etc.). The group may be integrated in the society in which it exists or not. If not, the individual inside a group is even less integrated. In a group one learns the emotional and social significance of different interpersonal or socio-personal aspects and configurations. Rejection and humiliation generate the most ample negative and long-term reaction. It represents denial of human values. Any individual will be ready to do anything to fight a system which rejects him, or he will go against it by means of suicidal behaviour. The resorts of any behaviour are either instinctive, emotional or rational. The fanatic has lost rational resorts, which implicitly suppose doubting. He is only left with emotional resorts and a reversed reason. De Unamuno (1982) says that the fanatic will use any idea. But this kind of personality already has a paranoid structure, which needs an idea in order to nest. The paranoiac — the product of natural evolution towards a rigid, stern and combative idea, in the name of justice-usually gets fixed on individual referential ideas of earthly level. The paranoiac, the fanaticised, - the product of bonsai type of personality forging - is fixed on a messianic idea with cultural origins at emotional individual level. Next, the messianic idea submits (by means of Uhtomski dominance type) the cognition's entire labour. Positive learning teaches the individual to be reflective, to ask questions. The reverse type of learning is "believe and faith" (in all religions) and teaches the individual to stop questioning and to accept the given assertions unconditionally. This type of idea embodiment causes atrophy, even death of an individual's reflective capacity, turning him into a social (and biological) slave. Similarly, the Roman culture raised and trained gladiators to kill each other in from of audiences. One indication "the good is alive/exists, so train to be the best”, canceled any other question or solution. We face "all or nothing” type of reactions without any nuances, still in total agreement with the culture which generates the idea or the paradigm, which in turn generates messianic ideas of religious type.

\section{The Fanatic's Relation with Culture}

As long as a culture generates fanatics who ghetto themselves and do not conflict with the society, this aspect 
does not significantly stick out and the fanatics in discussion only have a problem with themselves. However, any ghettoing leads to a feeling of exclusion, rejection or mistreatment which, in turn, leads to a justifying idea. When a justifying idea is clearly defined it identifies its target, it becomes an institution. The justifying idea is messianic, funding an existential paradigm. And paradigms have a "character of inevitable finality" (Horkheimer \& Adorno, 2012). The cultural factors can be divided into social, purely cultural and purely ideatic factors. Society is an expression of culture and socio-relational factors are derived from the underlying cultural principles of the society in discussion. From the social point of view, we must make note of what Millon and Grossman (2005) asserted: "social influences furnish a framework for how individuals learn to cope with the nature of their distress". From the perspective of fanaticism, every culture offers a different pragmatic frame, with similar final result. This means that the cultural frames for kamikaze, Taliban, Nazi officers are very different, yet the final result is extreme intolerance and self sacrifice with "vital risk".

In addition, we must see that our personality models do not correspond to the models in other cultures. A culture - by providing its own images, value criteria, contexts—-shapes the frame of thought, aspirations and, consequently, behaviour by means of example. Let us bear in mind that any unorphaned child is raised by their parents and that self-identification — a fundamental psychic process—-starts from models given by parents. Another note worth remembering: empirical factors to assess social risk factors for psychiatric disorders are difficult to measure" (Millon \& Grossman, 2005). This is valid in the case of fanatisation. We can identify them from the qualitative perspective, we can understand them from the logical point of view but we cannot yet pretend to be able to measure them. According to Kernberg (1978), a personality is forged by culture and can "organise itself pathologically, consistently and specifically" therefore, "it is not a transitory state". The organisation of personality starting from innate data, under the influence of culture and socio-relational peristatics factors can range from harmonious personality, accentuated personalities (an extreme form of these are the fanatics who border disharmonious personalities), disharmonious personalities (totally negative deviation from average) and "borderline personalities" (Kernberg, 1978) (particular structures of disharmonies) with relapse/decompensation moving towards transitory psychotic states. From this point of view, the intolerant fanatics have a harmonious normality in accordance with the messianic idea and a pathological side which cancels their compatibility with any other type of culture. However, things are not limited from this perspective. As we have already seen, fanatic messianic behaviour can be both sacrificial and terrorist, and a person can evolve between extremes on an axis of opposites within a lifetime. There are two consequences to this: 1) A possible dynamics of the personality structure, no matter how slow or relative. This is supported by the huge number of people who adhered to a messianic idea such as Nazism or communism and then crossed to the opposite side. 2) Due to the evolution on the axis of opposites, a personality can attain various levels of harmony or disharmony throughout his evolution, from light, medium to accentuated and pathological. Naturally, the fanatic's violent finality raises tricky problems but it is certain by now that the biological fund contributes a premise as well. Speaking of the ordinary, non-fanatic violence, Warren (Stone, 2005) studied a group of 250 non-psychic convicts who had committed crimes: the ones with paranoid and schizophrenic traits committed violent crimes, which suppose a certain genetic charge. But in the situation in which a person did not have a violence history and later became violent in the name of an idea, we are dealing with an alteration in the structure of the personality by mean of fanatisation. This is a violent reaction of predatory type without any emotional or vegetative input, without fear and with emotional indifference. This is a robotic type modification. How fast can the robotic fanatisation of a person happen? It depends on the "level of cultural input", on the behavioural models the given culture accepts at a given time.

Efficient propaganda can engage the majority of population, as it happened with Nazism, communism or as it currently happens with the fundamental Islamic movement. The current western society is guilty of consistently promoting violent behaviour by means of television and cinema (even in productions for children). They all praise violence, the hero who beats, kills, thus generating "warrior" models, especially in the case in which family or society does not provide the individual with the perspective of self-fulfillment. At a given moment, the offer "you can always be a hero fighting for us" can pose an emotional shock which changes the evolution course of a personality. We are engaged in a continuous self-construction. The western culture has a global nature, thus a global effect. In this way, western culture "culturally trains" the psycho-emotional immature people for violent behaviour. All is needed to complete the process is the fanaticism schools to plant the messianic idea. Naturally, it is practically essential to be able to track fanaticised individuals. As Leonard (1979) states, a personality can only be observed over the long term within his own environment. The fanatic controls his speech 
and behaviour outside his environment, as a consequence of possessing minimal intelligence. That is why collateral information is sometimes more important than psychological examination and clinical observation. Any behavioural, attitude, verbal "excrescence" can signal the iceberg of fanatical violence under covers, if the person comes from a culture which promotes violent fanaticism.

\section{The Christian/Muslim Ratio}

This is where Nietzsche's words seem harsh and dangerous through fanatic interpretation (Nietzsche, 1996) "as much justice and mercy as weakness". The potential danger lies in the possibility of seeing culture destroying a moral model to make room for another. The cult of ruthless power dedicated to a utopia which must kill "the dragon", for which it searches and if it is nowhere to be found, it is invented. In the case in discussion, we are referring to reducing morals to sacrifice in the service of the messianic idea. As with all religious or ideological messianic ideas, a "better world" is promised, whatever "better" means in each case. Man invented morals to be different from animals. Morals have always been justified by goals, principles and violence always involves a ratio of forces, which is a relation of ethological origin. Therefore, violence does not belong to morals, and, in order to put it within the moral frame, "the enemy must first be stigmatised, minimalised and demonized". This way he is despised and must be crashed and by crashing him "the world will be saved". The intolerance we have in the world flows from the heavens down and is caused by the principle of the "unique god". If he is unique, there can be no other. If another candidate to uniqueness shows up, he is the enemy of your god. This is the reason why the world of antiquity could not make sense of us today. Starting from here and from the pressing problem of integrating Muslims into the Christian world (or in any other world), we are trying, but their integration would be possible only if the Bible and the Quran were convergent. Not only are they non-convergent, but also they are presented as non-tolerant to each other. In vain does the Christian, the Mosaic, the Hindu or the Buddhist tell the Muslim "and this and that", as he will only accept "Allahu Akbar”.

The Bible, in its genetics, contains the seeds of Greek-Roman reasoning. It argues the irrational of the Christian mystery with the means elaborated by Greek-Roman thinking. This is the reason why, though the words of the Bible, the formidable sprouting, and then development of the European philosophical, scientific and technical thinking was made possible. The Quran is devoid of this kind of genetic intake of Greek-Roman reason, not arguing the mystery of Islamic faith, claiming the blind obedience of the "believe and do not inquire" type. This is the reason why the two teachings are incompatible. In addition, the Bible sanctions its followers through guilt, while the Quran sanctions through shame. The Bible allows forgiveness though penitence, while the Quran punishes, further predisposing the Islamic follower to more virulent acts of racism and intolerance than the Bible predisposes Christians. A detailed and competent analysis would emphasize the whole difference in reactive attitude's paradigm structure between the two religion-cultures.

This is where incompatibility starts. In the situation of present days, the compatibility solution seems hardly possible. In the long-term, religious leaders will or will not be able to offer a compatibility solution, but this is another issue, requiring to be judged by future generations that have not been born yet, unless it will be too late.

\section{References}

Carter, A. (1987). The Sadeian Woman: And the Ideology of Pornography. Pantheon Books, 242-238.

Cornuțiu, G. (2004). Psychological Basis of Medical Practice (Bazele psihologice ale practicii medicale) (Oradea Ed.). Imprimeriei de Vest, 84-94.

De Unamuno, M. (1982). Idiocracy in Spanish Essayists (Ideocrația în Eseiști Spanioli) (Ovidiu Drimba Ed.). Romania: Univers, 153.

Horkheimer, M., \& Adorno, T. W. (2012). Dialectic of Enlightenment (Romanian Ed.). Romania: Polirom, 105.

Kant, I. (1994). The Critique of Judgement (Romanian Ed.). Romania: București, 427-486.

Kernberg, O. M. (1978). Borderline Conditions and Pathological Narcisism; Lès troubles limites de la personalitate (French Ed.). Toulouse, France: Ed. Privat, 23-73.

Leonhard, K. (1979). Accentuated Personality (Romanian Ed.). Romania: Ed. Științifică și Enciclopedică, 12-254.

Millon, T., \& Grossman, S. D. (2005). Sociocultural Factors in Textbook of Personality Disorders. American Psychiatric Publishing, 223-234. 
Nietzsche, F. (1996). Thus spoke Zarathustra (Romanian Ed.) Romania: București, 238.

Noica, C. (2009). Stories of Man (Povestiri despre om). Bucharest, Romania: Humanitas.

Oldham, J. M., Skodol, A., \& Bender, D. (2005). Textbook of Personality Disorders. American Psychiatric Publishing.

Stone, M. H. (2005). Violence. In J. M. Oldham, A. Skodol, \& D. Bender (Eds.), Textbook of Personality Disorders (pp. 477-493). American Psychiatric Publishing. 